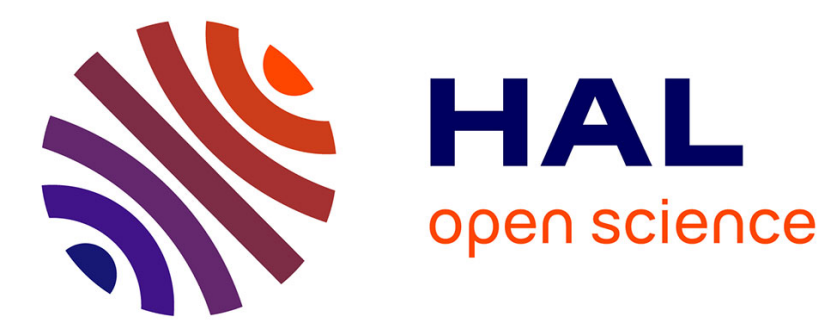

\title{
Learning from profession memories
}

Oswaldo Castillo, Nada Matta, Jean-Louis Ermine, Sophie Brutel-Mainaud

\section{To cite this version:}

Oswaldo Castillo, Nada Matta, Jean-Louis Ermine, Sophie Brutel-Mainaud. Learning from profession memories. ECAI'04: 16th European Conference on Artificial Intelligence, Aug 2004, Valencia, Spain. pp.1-7. hal-00432818

\section{HAL Id: hal-00432818 https://hal.science/hal-00432818}

Submitted on 7 Apr 2010

HAL is a multi-disciplinary open access archive for the deposit and dissemination of scientific research documents, whether they are published or not. The documents may come from teaching and research institutions in France or abroad, or from public or private research centers.
L'archive ouverte pluridisciplinaire HAL, est destinée au dépôt et à la diffusion de documents scientifiques de niveau recherche, publiés ou non, émanant des établissements d'enseignement et de recherche français ou étrangers, des laboratoires publics ou privés. 


\section{Learning from Profession Memories}

Oswaldo Castillo Nada Matta, Jean-Louis Ermine, Sophie Brutel-Mainaud

16th European Conference on Artificial Intelligence,

22 - 27 August 2004, Valence - Spain, 6 p. 


\title{
Learning from Profession Memories
}

\author{
Oswaldo Castillo $^{1}$ and Nada Matta ${ }^{2}$ and Jean-Louis Ermine ${ }^{3}$ and Sophie Brutel-Mainaud ${ }^{4}$
}

\begin{abstract}
Knowledge Management is a global process in the company. It includes all the processes that allow capitalization, sharing and evolution of the Knowledge Capital of the firm, now recognized as a critical resource of the organization. Several approaches have been defined to capitalize knowledge but few of them study the appropriation of that knowledge. In this paper we develop techniques based on knowledge and educational engineering, to enhance knowledge reuse in an organization. This knowledge is structured as profession memories.
\end{abstract}

\section{INTRODUCTION}

"The knowledge management indicates the management of all the knowledge and the know-how in action mobilized by the actors of the company to allow reaching its objectives" [1]. Several stages were identified in a process of knowledge management (knowledge capitalization and sharing) (Figure 1): It is about the externalization of crucial tacit knowledge of the company, the sharing of the knowledge capital made explicit in the form of memory, the appropriation and the exploitation of a part of these knowledge by the actors of the company [2].

Methods stemming from the knowledge engineering (such as MASK, REX, KOD, etc.) and the computer supported cooperative work (such as QOC, DIPA, etc.) [3] were developed in order to capitalize and make explicit knowledge in an organization. These methods allow defining corporate memories. A corporate memory is defined as the "explicit and persistent representation of the knowledge and the information in an organization" [3]. We can distinguish several types of memories: profession memory, project memory and organization memory.

The sharing and the appropriation of the corporate memories are still left by real blocking points within organizations. The methods of knowledge management are not sufficient to allow an effective appropriation of the knowledge by the actors of the company. However, the objective of a knowledge capitalization is indeed the sharing and the reuse of an experience with the aim of optimizing the process of organizational learning.

The technologies of information and the communication can support the knowledge distribution to favor the sharing. However, the distribution must be guided if we want to supply the good information at the right moment. Furthermore, the distribution of information is not enough to guarantee the reuse of the knowledge.

1 Tech-CICO, University of Technology of Troyes, Troyes, France email : oswaldo.castillo@utt.fr

Tech-CICO, University of Technology of Troyes, Troyes, France email : nada.matta@utt.fr

INT, Department Information Systems, Evry, France email : jeanlouis.ermine@int-evry.fr

IFTH, French Institute Textile - Clothing, Troyes, France email: sbrutel.ifth.org

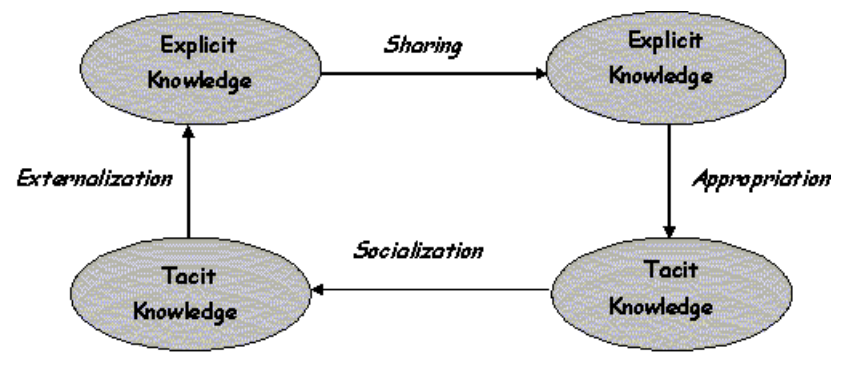

Figure 1. Process of the knowledge management (capitalization and sharing) adapted from [2]

One condition to reuse knowledge is to be assimilated by the actor and be integrated into his experiences base in order to generate appropriate knowledge at any time in the action [4].

On the other hand, the educational engineering offers learning means of the formalized knowledge. Several works in computer supported learning supply devices to guide knowledge structuring into units of study in order to be learned by students [5]. We suggest in this paper exploiting some of these techniques to guide the appropriation of the structured knowledge in a profession memory.

We define at first, the profession memory by presenting an example of this type of memory, extracted from a knowledge book [6]. We describe then the techniques which we exploited from the educational engineering in order to help in the appropriation of know-how made explicit in this type of memory.

\section{THE PROFESSION MEMORY}

We define a profession memory as the externalization of the knowledge produced in and for a given domain. It represents the problems solving strategy followed in a given activity. The techniques of knowledge engineering allow the formalization of this type of memory. Indeed, several approaches, such as MASK, REX, CommonKADS, or KOD [3], use techniques of knowledge engineering to extract knowledge, to formalize it in conceptual models where the knowledge that guides the problems solving is made explicit. The structure of this type of memory describes generally: the definition of the problem (or the process), the problem solving methods, as well as a description of manipulated concepts. This knowledge representation can lean on graphic presentations. For example, the models of problem solving of CommonKADS and MASK; with textual explanations such as experience feedback forms indexed with trees of concepts as it is the case of the elements of experience of REX [3].

For instance, a knowledge book represented with the MASK method [7] can illustrate a profession memory. In this book: 


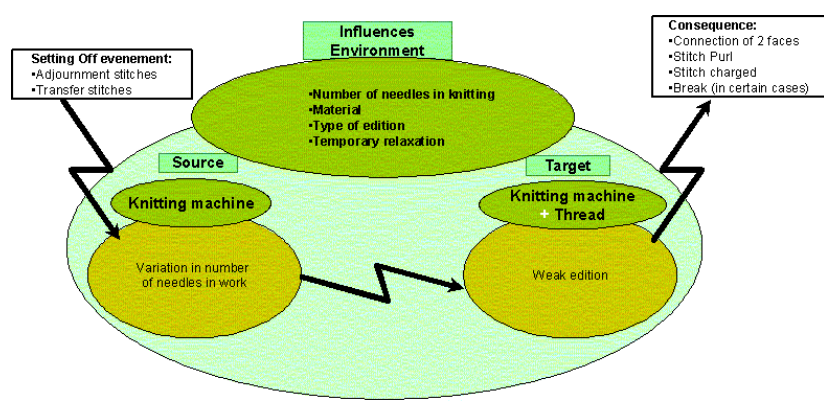

Figure 2. Example of profession memory, influence model, built with the MASK method.

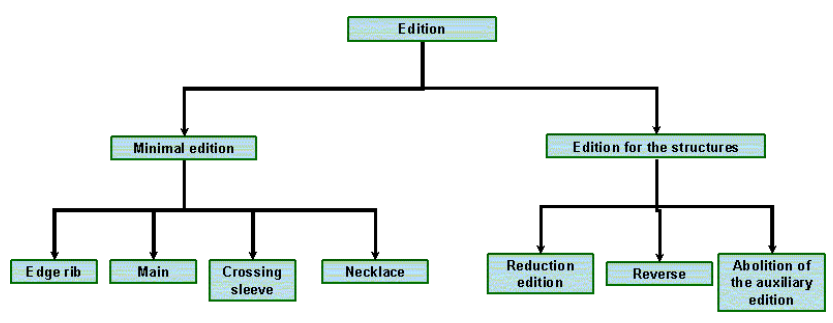

Figure 3. Example of profession memory, concept model, built with the MASK method

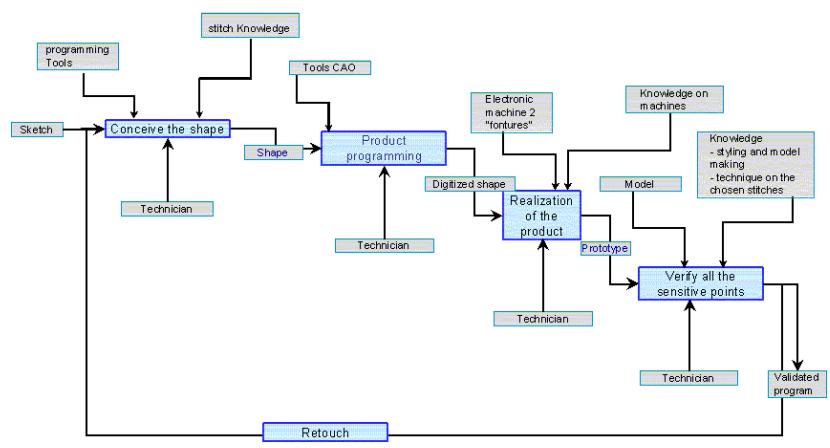

Figure 4. Example of profession memory, process model, built with the MASK method

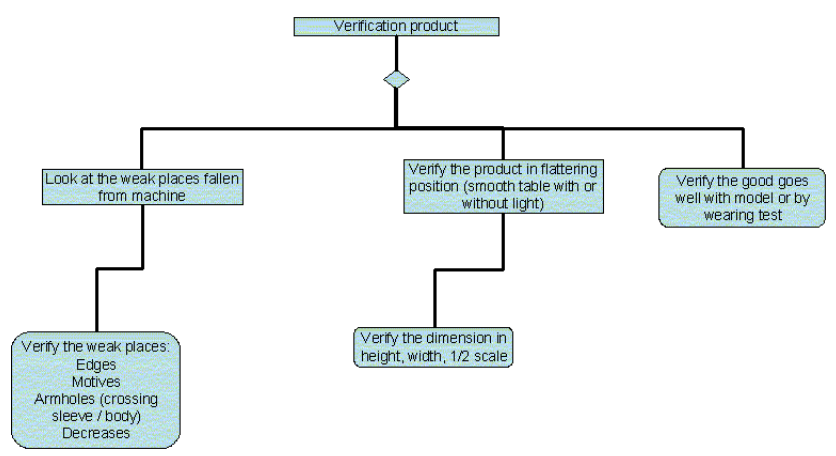

Figure 5. Example of profession memory, task model, built with the MASK method

- Domain knowledge is represented as influence model (Figure 2) and concept tree (Figure 3)
- Reasoning knowledge is described as process model (Figure 4) and task tree (Figure 5).

\section{THE EDUCATIONAL ENGINEERING}

According to Martial Vivet, "It is not enough to buy encyclopedia to learn knowledge! The knowledge spread on networks can be assimilated by human only if a main effort is made from didactic point of view, especially in the learning situations design" [8]. We intend to exploit on one hand, techniques of the educational engineering to define supports in the learning and on the other hand the knowledge engineering technique to make explicit the contents of this learning. We start thus by giving some key definitions of the educational engineering and the operational learning. Then we mention a typical architecture used in the computer-assisted learning.

"The educational engineering determines and sets up all the resources and the educational means aiming at facilitating the realization of trainings, by taking into account the objective, the contents and the public. It notably leans on the usage of information technologies and the communication for the education"

According to Paquette [5], by "educational engineering" or "training engineering" we indicate all the principles, the procedures and the tasks allowing of:

- Defining the contents of training by means of a structural identification of the knowledge and the aimed competence;

- Realizing an educational scenario of the activities defining the context of use and the structure of the learning materials;

- Defining infrastructures, resources and services necessary for the distribution of classes and maintaining their quality.

From the educational point of view, the knowledge is defined as "all the notions and the principles which a person acquires by the study, the observation and/or the experience and which it can be integrated into skills"2. For knowledge engineering and management, the knowledge is perceived as data, information, tasks and know-how, which the person uses in a practical way, to realize activities by creating new information.

According to dictionary, a competence is "a capacity to decide; recognized in a given subject"3. From the management point of view, a competence is "all the knowledge, the knowhow and the attitude to be expressed themselves in the precise frame of a working situation and which can be implemented without new learning"4. There are several families of competences: the operational competence which leads to the realization of a task, the technical competence which implies the use of a technical knowledge, the competence of behavior which implies to show an attitude or an arrangement, and the

\footnotetext{
${ }^{1}$ Cell of Educational Engineering. Education and Technology Department - Facultés Universitaires Notre-Dame de la Paix http://www.det.fundp.ac.be/cip

${ }^{2}$ Grand Dictionnaire terminologique http://www.granddictionnaire.com

${ }^{3}$ French dictionary Petit Larousse

${ }^{4}$ Grand Dictionnaire terminologique http://www.granddictionnaire.com
} 
administrative competence of management which are bound to the administration work ${ }^{5}$.

In our case, we aim at developing a learning system in order to increment operational competences of organization actors.

Various authors such as Rolland [9], Paquette [5], among others, propose methods of educational engineering to develop learning systems. The main objectives of these methods are: to cover all the activities of the educational engineering in an orderly and logical way, guide the realization of teaching equipments and plan the implementation of the infrastructure of technological and organizational support of the learning system. To develop a learning system most of the authors recommend at first to make an analysis for choosing the educational and training techniques, and then conceive, realize and validate teaching equipments and finally to prepare and to realize the implementation of the system.

According to Gilbert Paquette [5], the educational engineering leans on two processes in the heart of knowledge management:

- At first the extraction of the knowledge from domain experts or documents;

- Then the acquisition, by the organization actors, of the knowledge by learning; the transformation of the information in knowledge by means of the formal or informal activities taking a variety of forms and supports.

\subsection{The operational learning}

Generally, a profession memory, and especially a knowledge book, is organized so as to represent know-how in a given domain. It is rather about a practical knowledge acquired from the experience. The descriptions of the context, the problem solving methods as well as the evolution of the activity are not sufficient to establish a complete training on a profession. The learning techniques, which we intend to define, address mainly actors in a domain aiming to learn experience of an expert in this domain.

The complete training of an operator contains three phases: learning or intensification of the general knowledge; learning of procedures and typical solutions and training on a simulator in "real situations". This last phase is more recognized for operational learning [10]. During this phase, "the operational competence can be developed, and the expertise level is incremented. The student learns here of how to use knowledge learnt previously quickly, deliberately, in any situation and under any degrees of stress and workload". In her work, Kalina Yacef [10], found the following conclusions, from structuring of the operational training point of view:

- This one has to be made by the practice, in situation of action;

- This practice must be structured so as to respect the development of levels of expertise following the tasks and to be directed to purposes;

\footnotetext{
${ }^{5}$ Labor competence - International Work Organization http://www.ilo.org/publics/spanish/region/ampro/cintertos/temas/comp lab/doc/otros/infotep.htm
}

- The competence evolve with the practice, it is necessary to take measures of evaluation based on the result of the actions and not on the reasoning follow-up;

- The acquisition of competence is made on one hand by the automation of certain behavior and on the other hand by the development of capacities to solve new problems.

\subsection{The computer-assisted learning}

We chose to implement our operational training, as a system of individualized learning, based on activities of problems solving. These activities are described in a profession memory. We used the general architecture proposed for traditional system learning, which consists on [10], [11]:

- Expert module: represents the knowledge of the taught subject;

- Student model: the system must consider the student needs, its level, its difficulties and the state of its knowledge. Self [12] defines the student model from six functions "correction of the error, the assistant to the elaboration of an action to be begun when the error is due to an incomplete procedure, implementation by a global strategy to propose a new action plan, construction of a diagnosis, forecast of future actions (predictive function) and finally evaluation of the work supplied by the student";

- Teacher module: contains the educational expertise of the system, and has the role of planning and passing on the learning. This module is loaded with the management of contents, the prescription of the degree of difficulty of the problems or the subjects to be presented to the student. The economic planning of the training maybe realized in a dynamic, static or semi static way, or realized by the student or the instructor;

- Interface module: concerns the management of supports and the modes of communication of the system with the student.

The computer-assisted learning uses the simulation of situations problems and the development of exercises to help the student to acquire an expertise and increase his competence.

\section{PROPOSITION OF A TOOL OF KNOWLEDGE APPROPRIATION}

We thus try to show the difficulties of a domain and how to encounter them. It is for that reason; in our work we feel the need to exploit concepts of knowledge engineering especially the process of knowledge formalization. Indeed, the knowledge engineering techniques allow the emphasis of the difficulties of an activity while the educational engineering allows the estimation of the learning progress levels. We shall base our approaches on the one hand, on certain educational engineering evaluation techniques as diagnosis and problem solving learning and on the other hand on knowledge engineering techniques to extract and restructure the contents of the training and of the evaluations. The first postulate to be considered is the expert source of the knowledge has to participate as well in the 
construction of the profession memory as in the definition of the means of knowledge appropriation.

Let us note that an expertise is represented in a profession memory with models (model of task, activity, domain, etc.). These very useful models for the knowledge extraction are not easily accessible for knowledge appropriation. It is then important to reorganize the profession memory to answer the various needs of the organization actors.

We are going to suggest a tool of appropriation of an expertise and not knowledge on a domain studying. We are going to exploit the techniques of the educational engineering which allow supplying an environment of simulation of problems solving.

In our particular case, the expert module is represented by the content of the profession memory. But, as we said previously, this modeling is not sufficient to assure a complete training of the users. This memory has to be reorganized, for instance the domain of study. Otherwise, the expert is very busy developing activities of his work and he is almost not available to participate in the process of training and learning. It is necessary to notice as well, as in the industrial environment, it is difficult to assure the presence of a tutor to support the professional training.

Knowledge defined in a profession memory represents especially problems solving strategies. The evaluation of the learning of these strategies is not easy. We propose an autoevaluation which can be done by the student himself. In fact, the student can discover the expert strategy and adapt his problem solving approach. We do not believe that a comparison of results can allow an evaluation of the learning level of an organization actor. As we noted before, an expert cannot do this evaluation as well as a tutor in a basic learning system. We define techniques to guide this auto-evaluation. We present in the following our proposition in this aim.

\subsection{Definition of the domains of study}

To establish techniques of appropriation it is important to define the domains of study and the base of learning. These domains of study have to reflect the difficult points of the domain as well as the practical aspect. The identification of the domains of study can be thus guided according to two points of view:

- Domain: emphasizing the difficulties of the activity. The knowledge engineer has to guide the expert to identify the priority order of the memorized knowledge. For example, the expert can appoint that certain classifications or constraints are useful to understand the strategies of problems solving in a given domain. In another domain, the process of actions to be realized can support the understanding of the strategies and the behavior of the expert.

- Knowledge structure: identifying the nature of the memorized knowledge. The representation of the knowledge in a profession memory describes the role that plays the knowledge in the activity, and gives a semantic frame to guide interpretation and appropriation of problem solving strategies. For example, the control structures illustrate the rules that guide the progress of the activity; the process determines the context of this activity and the identification of the objectives to reach. Also, the concepts reflect a vision of the domain related to the actions.

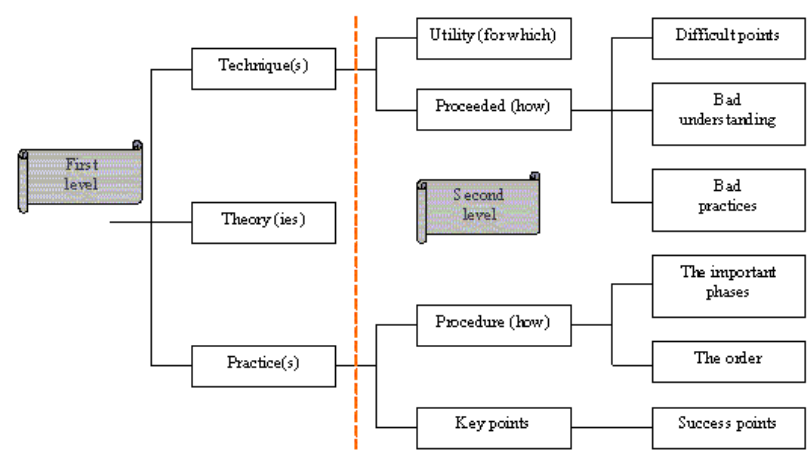

Figure 6. Tree of guidelines for the classification of domains of study and the construction of quizzes

We propose that the domains of study chosen by the expert can be classified as theoretical, technical and practical (Figure 6 - First level), According to its application in the organization.

We defined for every domain, the types of techniques of evaluation which we are going to use. We chose to make a number of quizzes related to some domain of study to make the student realize an analysis and a diagnosis on his learning of the corresponding domain. We also chose to make an exercise for every domain of study bound to the type of know-how, to show the expert problem strategies and the underlying controls.

We show in the following, the definition of these two techniques. At the moment, we did not work on cooperative exercises (who can support the global process of problem solving and emphasize the various aspects and the roles of the activity). The selection of every educational technique depends on the knowledge and the domain's point of view.

\subsection{Definition of quiz}

Quiz, as tool of formative evaluation in our case, are built from the conversations of externalization with the expert. The objective of the knowledge engineer is to help the expert to emphasize the difficulties of learning of its know-how, specifically the difficulties of the domain, the bad understandings and the bad practices (Figure 6). Domains of study are classified as theoretical, technical and practical. A decomposition of this classification can help the knowledge engineer to guide the expert to build the quiz questions (Figure 6 - Second level). Quiz is identified so as to advance the utility, the process and the key points of the domain.

The questions in an evaluation can be long opened answer, short opened answer, multiple choice, unique choice, true or false choice, multiple answer, crossing, among others. Quiz has to provide to student a support for every answer, as for example, by connections to related documents. A score at the end of every quiz helps the student estimate its level of learning.

We apply some of our propositions on a training experience in the pullover design domain. (Figure 7) shows an example of the quiz defined in this domain. The question emphasizes the important point to verify by showing the relations and the influence between some elements (transfer of stitch and edition). 


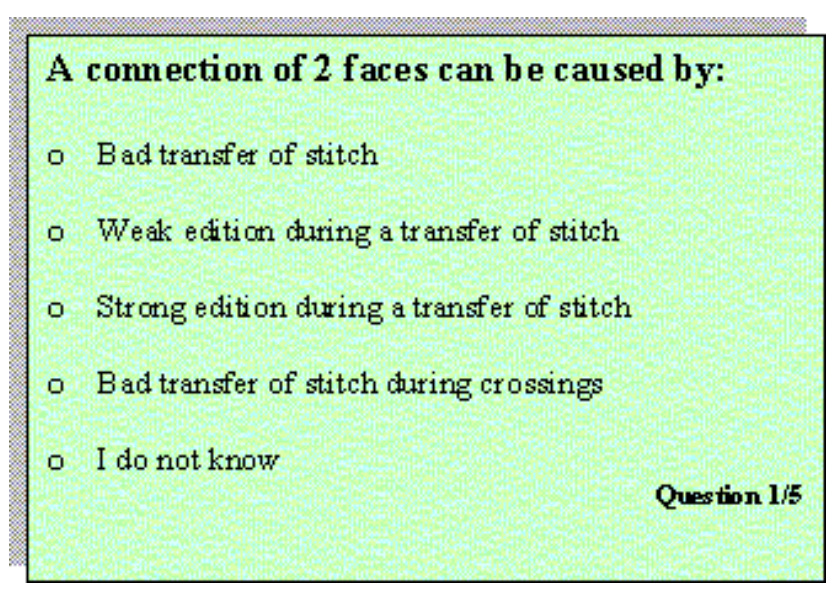

Figure 7. Example of a quiz, extracted from the pullover design application

\subsection{Definition of the exercises}

The standard exercises allow simulation of problem solving situations. This simulation is the most important in our case, because it is about learning of a practical knowledge.

The knowledge engineer guided by the representation of the know-how on the profession memory, can bring the expert to define all the parameters of a problem to be solved. The statement of the exercise is given by the expert himself. The knowledge engineer has to guide the expert in the design and the definition of the statement. This statement can contain small advices or suggestions which are going to guide the student to find a relevant solution for the problem. The expert has to assure the student an access to all the materials and the environment suited at the time of the exercise execution.

The objective of these exercises is to reveal to student the method followed by the expert to solve the problem. We did not want to use them in a purpose of evaluation by comparing the results. The student is invited to execute the corresponding stages of problems solving methods. He then discovers the laws of behavior which brought the expert to the way he solves the problem. The student can always find a help - or in the form of text, video, photo - to have a more precise idea on the task to be executed.

The expert, guided by the knowledge engineer, has to supply a prototype which allows the student to compare his answer found with the expected result. This prototype can be a list of the characteristics of the expected solution. A representation of the solution in the form of photo, video, etc., can also be helpful. The illustrated result has to show the student the miscellaneous characteristic and the minimal orders of the expected answer and the alternative characteristics which he can find.

(Figure 8) shows an example of this type of exercise. It consists of a verification of pullover which has been developed using 3D techniques. In this exercises we have a statement of the problem (verification of a pullover), guidelines (in which points, the verification must be done precisely), the task model (which represents the verification strategy of the expert), characteristics of the expected result (elasticity, colors, dimensions, etc.) and a photo (which illustrate the main point of verification).

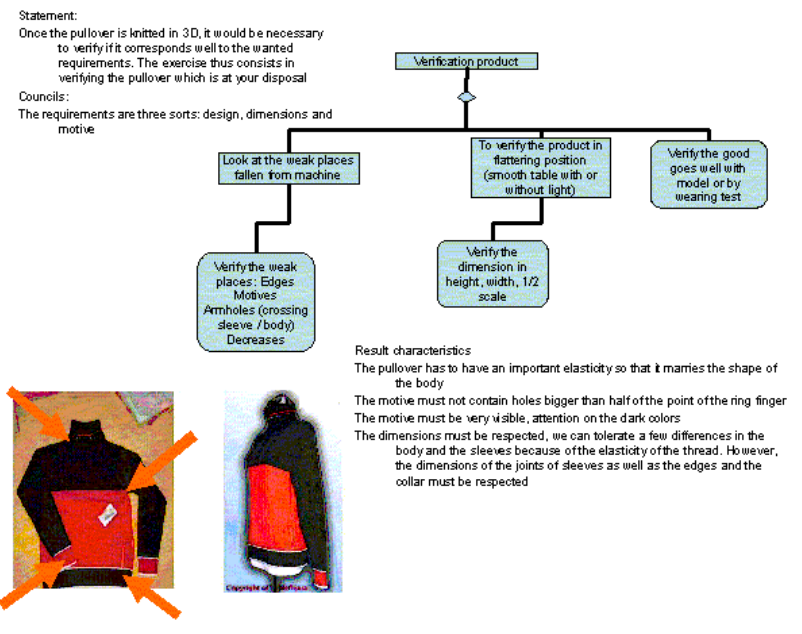

Figure 8. Example of a exercise, extracted from the pullover design application

\section{CONCLUSION}

The knowledge management is a process which contains as well the knowledge capitalization as the sharing and the appropriation of this knowledge. Several techniques of knowledge capitalization were defined. These techniques inherit for the most part of the methods of knowledge engineering. However, the appropriation of the knowledge remains another subject to be explored. The phase of appropriation requires a quite particular attention because of its success will depend on the efficiency of the organizational learning and thus the performance of the company partially.

On the other hand, the techniques of educational engineering, study-learning techniques and supply devices (teaching equipment, tools of evaluation and process of learning) of assistant to the appropriation of the knowledge. We studied these techniques to supply a device of appropriation of knowledge formalized in the form of memory.

We emphasized in this study the learning of the practice of problem solving described in a profession memory. The learning tools, we defined, especially techniques of evaluation that the student exploits as well as acquire the know-how of the expert as to estimate his level of learning. Also, the objective of this learning is to reveal the difficulties of the activity. The techniques of knowledge engineering such as the conversations of externalization guided by classifications and other types of guidelines are very useful in the definition of the underlying teaching equipment.

Actually, we have worked on the definition of the expert module for our proposition of tools for training. We aim then, at defining student model in our case.

We are developing software that supports our approach, especially the exercises execution and the learning process. We first apply our approach on an expertise of knowledge capitalization with MASK and on the textile domain. This expertise is represented as a knowledge book [7].

We aim at studying the appropriation from other type of professions memories representation such as CommonKADS models or experience feedback forms (defined with REX) [3]. 


\section{REFERENCES}

[1] J. Charlet, M. Zacklad, G. Kassel, D. Bourigault, 'Ingénierie des Connaissances - Recherches et Perspectives', Ingénierie des Connaissances - Evolution et nouveaux défis, Eyrolles, 1999.

[2] I. Nonaka, H. Takeuchi, The knowledge - Creating Company: How Japanese Companies Create the Dynamics of Innovation, Oxford University Press, 1995.

[3] R. Dieng-Kuntz, O. Corby, F. Gandon, A. Giboin, J. Golebiowska, N. Matta, M. Ribière, Méthodes et outils pour la gestion des connaissances, $2^{\mathrm{e}}$ edition, Dunod éditeur, 2001.

[4] T. Tounkara, N. Matta, J.L. Ermine, C. Coppens, 'L'appropriation des connaissances avec MASK', In proceedings of Extration et gestion des connaissances EGC'2002 (Industrial session), Montpellier, 2002.

[5] G. Paquette, L'ingénierie pédagogique. Pour construire l'apprentissage en réseau, Presses de l'université de Québec, 2002.

[6] N. Matta, J.-L. Ermine, G. Aubertin, J.-Y. Trivin, 'Knowledge Capitalization with a knowledge engineering approach: the MASK method', In proceedings of IJCAI'2001 workshop on Knowledge Management and Organizational Memory, 2001.

[7] J.-L. Ermine, La gestion de connaissances, Hermès sciences publications, 2002.

[8] E. Bruillard, Les Machines à Enseigner, Hermes éditeur, 1997.

[9] M. Rolland, Bâtir des formations professionnelles pour adultes, Editions d'Organisations, 2000.

[10] K. Yacef, Vers un Assistant Tutoriel Intelligent pour la Formation d'Opérateurs de Systèmes Complexes et Dynamiques, Université René Descartes - Paris V, Soutenue le 27 octobre 1999.

[11] R. Wigetman, Vers la conception du système Sieel : un tuteur intelligent pour le contrôle aérien, Université Paul Sabatier de Toulouse - Toulouse, Soutenue le 17 novembre 1994.

[12] J. Self, 'By passing the intractable problem of student modelling', In proceedings of Intelligents Tutoring Systeme Conference, C. Frasson \& G. Gauthier (Eds). Pp 18-24. 